\begin{tabular}{|l|l|l|l|l|l|}
\hline J. Tek. Ling & Vol. 12 & No. 1 & Hal. 17 - 23 & Jakarta, Januari 2011 & ISSN 1441-318X \\
\hline
\end{tabular}

\title{
ANALISIS KESEDIAAN MEMBAYAR JASA LINGKUNGAN DALAM PENGELOLAAN SUMBERDAYA AIR MINUM TERPADU DI INDONESIA (STUDI KASUS DAS CISADANE HULU)
}

\author{
M. Fauzi Sutopo'), Bunasor Sanim²), Yusman Syaukat'3), M. Ikhwanuddin Mawardi4) \\ ${ }^{1)}$ Mahasiswa Program Doktor (S3), SPs IPB, \\ Program Studi Pengelolaan Sumberdaya Alam dan Lingkungan \\ ${ }^{2)}$ Guru Besar Tetap IPB, Bidang Ilmu Ekonomi Sumberdaya dan Lingkungan \\ 3) Staf Pengajar Fakultas Ekonomi dan Manajemen, Institut Pertanian Bogor \\ Peneliti di Pusat Pengkajian dan Penerapan Teknologi Lingkungan, \\ Badan Pengkajian dan Penerapan Teknologi
}

\begin{abstract}
Ecocentrism paradigm in development are intended to ensure the sustainability of water resources in the future for future generations. The research methodology was conducted with the model approach to drinking water users willingness to pay for environmental services (YWTP). The results in Analysis Willingness to Pay in Drinking Water Management in the Upstream Watershed Cisadane illustrates that the existence of a positive response from drinking water users (entrepreneurs) to be willingness to pay for environmental services (YWTP) as payment and reward for environmental services to the public because it is influenced by the presence and the beneficiaries are significantly linearly with level of education (sig. 0.041) and Variable in YWTP education significant at 95\% confidence level. Policy implications of this research that the user (downstream) is willingness to pay (WTP) for environmental services with averaging Rp1 $538.65 \mathrm{per} \mathrm{m}^{3}$ as payment or reward for environmental services to society (upstream), so the Government (Local) PES has a potential revenue to fund conservation of Rp106.94 billion per years, but in current conditions the government only earns Rp20.57 billion per year, so that only reached $19.24 \%$.
\end{abstract}

Keywords: Paradigm Ecocentrism, Willingness to Pay (WTP), Payment for Environmental Services (PES), and Return on Environmental Services.

\section{PENDAHULUAN}

Sumberdaya air merupakan sumberdaya alam yang merupakan unsur paling esensial dan penentu terpenting dalam kehidupan setiap makhluk hidup serta pada kondisi tertentu dapat merupakan faktor yang menentukan terhadap tingkat kemakmuran suatu masyarakat bangsa. Dengan demikian air merupakan sumberdaya alam yang sangat strategis dan vital bagi kehidupan manusia dan pembangunan serta keberadaannya tidak digantikan oleh materi lainnya. Dalam hal ini, air dibutuhkan untuk menunjang berbagai sistem kehidupan baik dalam lingkungan atmosfir, litosfir dan biosfir; sehingga pasokan air yang 
mendukung berjalannya pembangunan dan berbagai kebutuhan manusia perlu dijamin kesinambungannya terutama kuantitas dan kualitasnya.

\subsection{Latar Belakang}

Air bersifat barang publik menjadi barang ekonomis yang semakin strategis, maka pemanfaatan sumberdaya air (baku) bersih menimbulkan tiga jenis persaingan (competitions), yaitu: (1) persaingan antarindividu atau kelompok pengguna (antara pihak-pihak kelompok kaya dan miskin atau kelompok berdaya dan tidak berdaya) dalam satu generasi, (2) kompetisi spasial misalnya antara desa dan kota, antara hulu dan hilir, ataupun (3) persaingan temporal antara generasi saat ini dan generasi mendatang bagi keperluan kehidupan. Oleh karena itu sumberdaya air baku akan menjadi barang dan jasa strategis dan penting yang harus dinilai secara ekonomi.

Adanya kompetisi dalam pengalokasian sumberdaya air haruslah ditangani dengan baik, menuju kearah perbaikan efisiensi dan keadilan (equity) agar tidak terjadi kemubaziran dan tidak mengarah kepada ketidakberlanjutan atau kelangkaan atau water scarcity ${ }^{1}$. Dengan perkataan lain, penyediaan (supply) sumberdaya air baku dapat menjadi semakin kritis, sementara permintaannya terus meningkat sehingga akan mengalami banyak kejadian periode defisit air. Sebagai ilustrasi, berdasarkan kriteria yang dikeluarkan PBB kebutuhan air bagi penduduk setiap tahunnya adalah sebesar $1.100 \mathrm{~m}^{3} / \mathrm{kapita/}$ tahun $^{2)}$, dengan menggunakan data dasar 2007 maka pada tahun 2015 akan terjadi defisit air sebesar $649.26 \mathrm{~m}^{3} / \mathrm{kapita} /$ tahun dengan tingkat pertumbuhan defisit air tahunan 4,36\% sementara kalau menggunakan 4 sehat 5 sempurna (780 $\left.\mathrm{m}^{3} / \mathrm{kapita} / \mathrm{tahun}\right)$ pada tahun 2015 terjadi defisit air $324.26 \mathrm{~m}^{3} / \mathrm{kapita} /$ tahun dengan tingkat pertumbuhan defisit air tahunan $7,63 \%{ }^{3)}$.

Pelibatan pengguna jasa lingkungan di wilayah hilir seperti pengelola atau pemanfaat (pengusaha) air minum dalam menyediakan biaya konservasi produktif di wilayah hulu merupakan alternatif atau pilihan yang konstruktif dalam pembiayaan pengelolaan usaha air minum di DAS Cisadane hulu. Pembiayaan atas pemanfaatan jasa lingkungan sumberdaya air yang menganut dasar filosofis users pay principle adalah pembayaran jasa lingkungan (PJL). PJL memberikan arti penting dalam hal keberlanjutan sumberdaya air, mengapa?. Pertama, karena masih banyak orang yang belum mendapatkan jasa lingkungan yang layak atas sumberdaya air. Kedua, potensi perkembangan pemasaran jasa air pada saat sekarang cukup menjanjikan. Ketiga, bahwa konsep PJI air ini dibangun dengan kerangka pikir hubungan hulu dan hilir. Keberadaan air di dataran rendah atau oleh para pemanfaat air dalam hal ini hilir sangat bergantung pada ketersediaan air yang ada di kawasan hulu, sehingga menciptakan reward atau penghargaan yang diberikan oleh para pemanfaat air yang diwujudkan dalam kerangka pembayaran jasa lingkungan. Menurut Kristrom 2002 dalam Bergh 2002 bahwa pendekatan nilai pembayaran jasa lingkungan dapat dilakukan dengan contingent valuation method (CVM) yang dapat dianalisis dengan kemauan membayar atau willingness to pay atau WTP ${ }^{4}$. Menurut Fauzi (2006) WTP adalah keinginan membayar seseorang terhadap barang dan jasa yang dihasilkan oleh sumberdaya alam dan lingkungan ${ }^{5}$.

\subsection{Tujuan}

Tujuan penelitian ini, yaitu:

(1) Mengkaji pengetahuan dan apresiasi pengelola atau pemanfaat air minum di DAS Cisadane hulu dalam hubungannya dengan pembayaran jasa lingkungan.

(2) Menganalisis nilai kemauan membayar (WTP) pemanfaat atau pengguna air minum dan faktor-faktor yang mempengaruhinya.

(3) Melakukan sintesa kebijakan sebagai implikasi penelitian dalam kesediaan 
pemanfaat air minum untuk membayar jasa lingkungan dalam pengelolaan air minum di DAS Cisadane hulu.

\section{METODOLOGI PENELITIAN}

\subsection{Waktu dan Lokasi Penelitian}

Penelitian dilaksanakan dari November 2009 - Juni 2010. Penelitian ini dilakukan di DAS Cisadane hulu, meliputi kecamatan-kecamatan Ciawi, Caringin, Cijeruk, Cigombong, Tamansari, dan Ciomas Kabupaten Bogor.

\subsection{Penetapan Responden Contoh}

Penetapan responden dengan metode acak sederhana dan sengaja dan metode stratifikasi dengan sengaja yaitu: (1) persepsi karyawan perusahaan dan PDAM terhadap WTP 36 responden $\left(Y_{\text {WTP }}\right)$, (2) keragaman air minum: pengusaha air perorangan, badan usaha swasta (39 responden) dan 2 lembaga PDAM, (3) pejabat terkait dengan pengelolaan sumberdaya air 8 responden, (4) pakar sumberdaya air dan lingkungan 1 responden.

\subsection{Model}

Model dalam penelitiaan ini adalah menggunakan model persamaan regresi logistik baik pada model perilaku Pengelola air minum dalam kesediaannya membayar jasa lingkungan.

$$
P_{i}=E\left(Y=1 \mid X_{i}\right)=\frac{e^{\ln (P x / 1-P x)}}{1+e^{\ln (P x / 1-P x)}}
$$

Kemudian dari model persamaan regresi logistik multinomial, menjadi Model Persamaan Regresi Berganda:

Model Analisis Willingness to Pay $\left(Y_{\text {WTP }}\right)$ :

$$
\operatorname{Ln}(P X / P 1-P X)=Y_{W T P}
$$

Keterangan:

$\mathrm{P}_{\mathrm{x}} / \mathrm{P}_{1}-\mathrm{P}_{\mathrm{x}}=$ Odd ratio, merupakan perbandingan peluang pengelola air minum yang bersedia membayar (WTP dengan pengelola air minum (responden) yang tidak bersedia membayar.

$\mathrm{P}_{(\mathrm{xi})} \quad=$ Peluang Pengelola Air Minum kesediaannya untuk membayar atau WTP ( 1 = Ya; 0 = Tidak $)$

$\alpha=$ Konstanta

$\mathrm{X}_{1}=$ Umur

$\mathrm{X}_{2}=$ Tingkat Pendidikan

$\mathrm{X}_{3}=$ Jumlah tanggungan keluarga

$\mathrm{X}_{4} \quad=$ jenis Pekerjaan

$\mathrm{X}_{5} \quad=$ Pendapatan (Rp per bulan)

$\mathrm{X}_{6} \quad=$ Jenis kelamin

$\mathrm{X}_{7}=$ Pandangan terhadap PJL

$\mathrm{X}_{8} \quad=$ Pandangan terhadap masyarakat di hulu

$\mathrm{X}_{9}=$ Pandangan terhadap masyarakat melakukan konservasi

$\mathrm{X}_{10}=$ Insentif bagi masyarakat di hulu

$\mathrm{X}_{11}=$ Pengaturan Mekanisme PJL

$\mathrm{X}_{12} \quad=$ Persepsi pentingnya PJL

$\mathrm{X}_{13}=$ Jarak rumah ke sumber mata air

$\mathrm{X}_{14}=$ Pengalaman atau lama bekerja

$\beta_{1} \ldots \beta_{14}=$ Koefisien regresi

$\varepsilon \quad=$ Kesalahan dalam persamaan atau gangguan

\subsection{Metoda Analisis}

Analisis terhadap peubah bebas yang berpengaruh terhadap perilaku pengguna (pemanfaat) air baku air minum di DAS Cisadane Hulu akan dilakukan dengan pendekatan análisis faktor ${ }^{6}$, dengan pendekatan análisis komponen utama

$$
\begin{aligned}
Y_{\text {WTP }}= & \alpha+\beta_{1} X_{1}+\beta_{2} X_{2}+\beta_{3} X_{3}+\beta_{4} X_{4}+\beta_{5} X_{5}+\beta_{5} X_{6}+\beta_{7} X_{7} \\
& +\beta_{8} X_{8}+\beta_{9} X_{9}+\beta_{10} X_{10}+\beta_{11} X_{11}+\beta_{12} X_{12}+\beta_{13} X_{13}+\beta_{14} X_{14}+\varepsilon
\end{aligned}
$$


(AKU) atau principal component analysis (PCA) sebagai suatu metoda untuk meniadakan (extraction method) peubah bebas yang tidak penting terhadap variabel atau peubah yang dimungkinkan berpengaruh terhadap perilaku pemanfaat air minum apakah bersedia membayar jasa lingkungan ataukah tidak bersedia. Penggunaan analisis faktor diperlukan untuk melakukan penapisan variabel mana yang bisa dimasukan dalam persamaan model atau untuk mendapatkan peubah baru yang saling ortogonal atau bebas dan membuat plot obyek dalam dimensi yang lebih kecil yang merupakan análisis antara untuk analisis regresi, termasuk análisis regresi logistik multinomial atau multinomial logistic regression ${ }^{7}$.

\section{HASIL DAN PEMBAHASAN}

\subsection{Keragaan Ketersediaan dan Neraca Air di DAS Cisadane Hulu}

Ketersediaan (stok) sumberdaya air di lokasi penelitian DAS Cisadane hulu rata-rata ketersediaan air tanah mencapai 249.55 juta $\mathrm{m}^{3}$ per tahun atau sekitar 7 913.18 liter per detik bila perhitungan berbasis hidrologi dan bila perhitungan berbasis Cadangan Air Tanah (CAT) Bogor sebesar 527.5 juta $\mathrm{m}^{3}$ per tahun atau sekitar 16726.92 liter per detik, sehingga hasilnya diperkirakan rata-rata mencapai 388.53 juta $\mathrm{m}^{3}$ per tahun atau sekitar 12 320.21 liter per detik.

Ketersediaan air permukaan, salah satu indikasinya diukur dari Debit Sungai Cisadane dimana neraca airnya masih mengalami surplus yang relatif tinggi sepanjang tahun dalam setiap bulan baik pada musim kemarau maupun pada musim hujan karena debit andalan masih lebih besar dari debit kebutuhan akan air bersih, dimana Qmin andalan terjadi pada Agustus 3.400 l/detik sementara Q kebutuhan 1.653 I/detik masih terjadi surplus sebesar 1.747 I/detik.

\subsection{Menetapkan Model $Y_{\text {wTP }}$ di DAS Cisadane Hulu}

Hasil análisis faktor (tiga tahap) dengan pendekatan análisis komponen utama berupa metoda penapisan (extraction method) dengan PCA terhadap variabel yang ada menunjukkan bahwa variabel-variabel: umur responden, tingkat pendidikan, tanggungan keluarga, jenis pekerjaan, pendapatan per bulan, pandangan terhadap PJL, pandangan terhadap masyarakat di hulu, pandangan terhadap masyarakat dalam melakukan konservasi, insentif bagi masyarakat di hulu, persepsi terhadap pentingnya kemauan membayar, dan pengalaman atau lama bekerja merupakan variabel-variabel yang akan dianalisis dan diduga mempengaruhi kemauan atau kesediaan (perusahaan) untuk membayar (WTP) dengan menggunakan model persamaan regresi logistik.

Hasil pengolahan data atau sintesis model bahwa terdapat $61,11 \%$ setuju bahwa perusahaan pemanfaat air baku air minum berkemauan untuk membayar jasa lingkungan (WTP) dan hasil determinasi model disajikan pada Tabel 1.

Tabel 1 Determinasi Model

Model Summary

\begin{tabular}{|c|c|c|c|}
\hline Step & $\begin{array}{c}-2 \text { Log } \\
\text { likelihood }\end{array}$ & $\begin{array}{c}\text { Cox \& } \\
\text { Snell R } \\
\text { Square }\end{array}$ & $\begin{array}{c}\text { Nagelkerke } \\
\text { R Square }\end{array}$ \\
\hline 1 & $20.802 \mathrm{a}$ & .532 & .721 \\
\hline
\end{tabular}

a. Estimation terminated at iteration number 8 because parameter estimates changed by less than .001 .

Nilai Nagelkerke R Square Pada model ini nilai adalah 0,721 , dimana nilainya mendekati angka satu sehingga model ini relatif lebih baik. Nilai Nagelkerke $R$ Square menunjukkan seberapa besar pengaruh variabel-variabel penduga dalam menentukan peluang responden bersedia 
membayar (WTP). Tampak dengan Nilai Nagelkerke R Square $72,1 \%$, artinya secara bersama-sama, semua variabel penduga menentukan $72,1 \%$ peluang responden untuk bersedia membayar, sementara $27,9 \%$ adalah pengaruh variabel lain yang tidak diamati dalam penelitian. Menurut Mitchell dan Carson (1989), niali $R$ square dalam penelitian ekonomi sumberdaya alam dan lingkungan dapat ditolerir sampai dengan $15 \%$. Model YWTP ini lebih baik ${ }^{8}$.

Hasil pengolahan data yang dihasilkan pada Variables in the Equation maka nilai koefisien dari setiap peubah pada model persamaan regresi logistik WTP disajikan pada Tabel 2.
Berdasarkan hasil analisis dari model regresi logistik WTP maka koefisien variabel dari model WTP tersebut yang signifikan adalah variabel pendidikan (sig. 0,041*)) pada $P$-Value lebih kecil daripada 0,05 ( $\alpha$ $=0,05$ ). Berarti hanya ada 1 variabel yang secara signifikan sangat berpengaruh terhadap model WTP yaitu variabel tingkat pendidikan responden. Artinya setiap kenaikan (penurunan) 1 unit tingkat pendidikan mengakibatkan terjadi kenaikan (penurunan) 3.375 kali kemauan untuk membayar (WTP); dengan kata lain bila terjadi kenaikan kemauan untuk membayar jasa lingkungan dari para pengguna atau pemanfaat air baku air minum sebesar 3.375

Tabel 2 Nilai Koefisien pada Peubah Perilaku Perusahaan Bersedia Membayar Jasa Lingkungan di DAS Cisadane Hulu, 2010

\begin{tabular}{|l|l|r|r|r|r|r|r|}
\hline \multicolumn{7}{|c|}{ Variables in the Equation } \\
\hline & & \multicolumn{1}{c|}{ B } & \multicolumn{1}{c|}{ S.E. } & \multicolumn{1}{c|}{ Wald } & Df & \multicolumn{1}{c|}{ Sig. } & Exp(B) \\
\hline Step 1a & Umur & -1.995 & 1.433 & 1.938 & 1 & .164 & .136 \\
\hline & Pendidikan & 3.375 & 1.653 & 4.170 & 1 & .041 & 29.235 \\
\hline & Tanggungan & .224 & .446 & .252 & 1 & .616 & 1.251 \\
\hline & Pekerjaan & 3.831 & 3.092 & 1.536 & 1 & .215 & 46.109 \\
\hline & Pendapatan & -1.285 & 1.370 & .879 & 1 & .348 & .277 \\
\hline & PandanganPJL & -.453 & 1.754 & .067 & 1 & .796 & .636 \\
\hline & PMasyarakat & -.624 & 1.028 & .369 & 1 & .543 & .536 \\
\hline & MasyKonservasi & 1.522 & 1.093 & 1.938 & 1 & .164 & 4.581 \\
\hline & Insentif & .079 & 1.057 & .006 & 1 & .941 & 1.082 \\
\hline & PersepsiWTP & .561 & .726 & .598 & 1 & .439 & 1.752 \\
\hline & Pengalaman & .371 & .318 & 1.363 & 1 & .243 & 1.450 \\
\hline & Constant & -16.773 & 11.272 & 2.214 & 1 & .137 & .000 \\
\hline
\end{tabular}

a. Variable(s) entered on step 1: Umur, Pendidikan, Tanggungan, Pekerjaan, Pendapatan,

PandanganPJL, PMasyarakat, MasyKonservasi, Insentif, PersepsiWTP, Pengalaman. Sumber: Data Primer. Hasil Penelitian. Data Diolah.

Adapun Model persamaan regresinya regresi multinomial, adalah:

$$
\begin{aligned}
Y_{\text {WTP }}=\quad & \left.-16,773-1,995 X_{1}+3,375 X_{2}^{*}\right)+0,224 X_{3}+3,831 X_{4}-1,285 X_{5} \\
& -0,453 X_{6}-0,624 X_{7}+1,522 X_{8}+0,079 X_{9}+0,561 X_{10}+0,371 X_{11}
\end{aligned}
$$


kali maka tingkat pendidikan responden terjadi pula kenaikannya.

Nilai rataan kesediaan perusahaan membayar (WTP) jasa lingkungan adalah $\mathrm{Rp} 1538.65$ per $\mathrm{m}^{3}$ sebagai kompensasi atas pengelolaan air minum di DAS Cisadane hulu, disajikan pada Gambar 1. pendapatan, pandangan terhadap PJL, pandangan terhadap masyarakat di hulu, pandangan terhadap masyarakat dalam melakukan konservasi, insentif bagi masyarakat di hulu, persepsi pentingnya kemauan membayar, pengalaman atau lama bekerja.

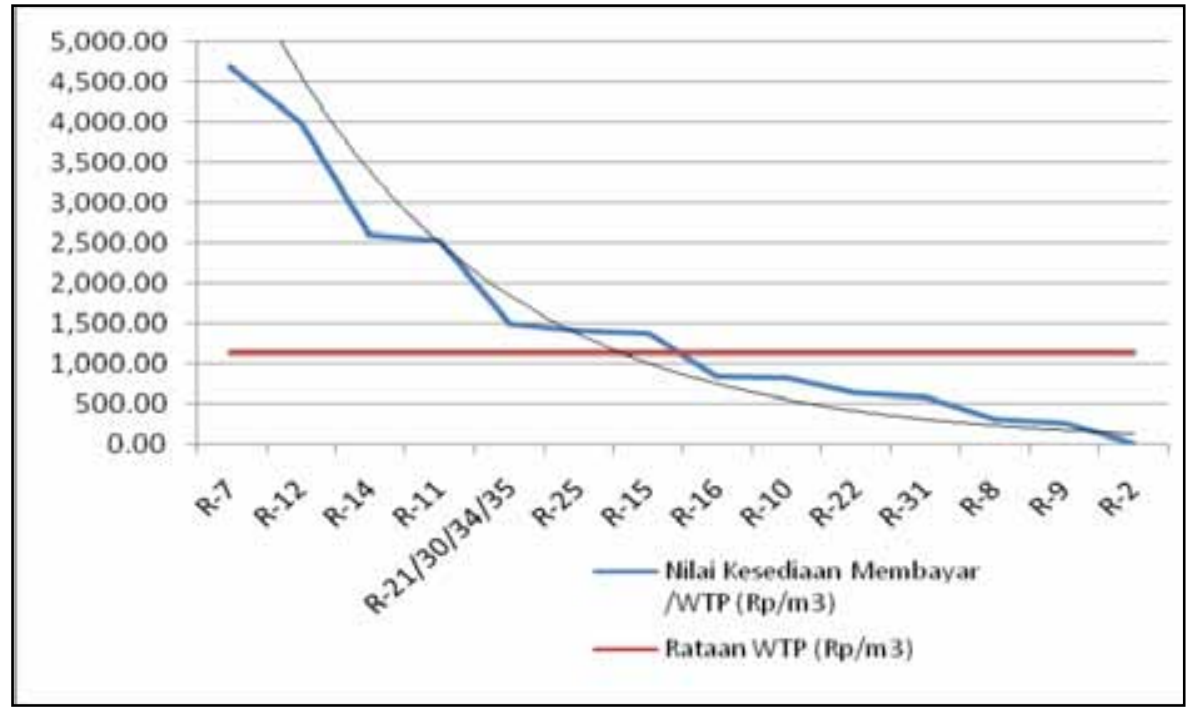

Gambar 1 Keragaan Nilai WTP dan Rataan WTP

Potensi dana kompensasi berupa pembayaran jasa lingkungan yang relatif besar sebagai biaya konservasi untuk penyedia jasa di wilayah hulu DAS Cisadane dari berbagai kelompok pengelola usaha air minum sebagai pengguna jasa lingkungan (users pay principle) di hilir dalam pengelolaan air minum untuk tujuan perbaikan kualitas hidup masyarakat di hulu sebesar Rp 106,94 miliar per tahun, sementara pada kondisi saat ini Pemerintah hanya menerima Rp 20,57 miliar per tahun, sehingga baru mencapai $18,93 \%$.

\section{KESIMPULAN DAN SARAN}

\subsection{Kesimpulan}

1. Peubah yang berpengaruh terhadap YWTP: umur responden, tingkat pendidikan, jumlah tanggungan keluarga, jenis pekerjaan,
2. Peubah yang signifikan pada $Y_{\text {WTP }}$ adalah peubah pendidikan.

3. Terdapat potensi dana kompensasi sebagai biaya konservasi untuk penyedia jasa di wilayah hulu dari berbagai kelompok pengelola usaha air minum sebagai pengguna jasa lingkungan (users pay principle) atas dasar nilai rataan WTP sebesar Rp. $1.538,65$ per $\mathrm{m}^{3}$ yaitu Rp 106.94 miliar per tahun, sementara pada kondisi saat ini Pemerintah hanya menerima Rp20.57 miliar per tahun, sehingga baru mencapai $19.23 \%$.

4. Rataan nilai WTP Rp $1.538,65$ per $\mathrm{m}^{3}$ merupakan basis perhitungan dasar tentang nilai pembayaran dan/atau imbal jasa lingkungan di DAS Cisadane hulu oleh para pengelola air (users pay principle) kepada masyarakat di hulu melalui Pemerintah Daerah sebagai regulator dan fasilitator kebijakan. 


\subsection{Saran}

Implementasi kebijakan untuk penerapan pajak air tanah yang akan diberlakukan pada Kabupaten atau Kota mulai 2011 sesuai dengan UU No. 28 Tahun 2009 tentang Pajak Daerah dan Retribusi Daerah agar disinkronisasikan dengan memasukkan UU No. 32 Tahun 2009 tentang Perlindungan dan Pengelolaan Lingkungan Hidup dengan (1) kompensasi atau imbal jasa lingkungan; (2) dana jaminan pemulihan lingkungan hidup dan bantuan untuk konservasi; (3) terkait dengan sistem insentif dan disinsentif, pentingnya pembayaran jasa lingkungan hidup. Hal ini agar diterapkan baik dalam Peraturan Daerah tentang Pengelolaan Air Tanah maupun Peraturan Daerah tentang Pajak Air Tanah tingkat Kabupaten atau Kota, dan Pengelolaan Aor Permukaan dan Pajak Air Permukaan oleh Pemerintah Propinsi Jawa Barat sehingga besarnya nilai pembayaran jasa lingkungan sebagai instrumen pendanaan lingkungan dalam pengelolaan sumberdaya air minum secara eksplisit nilainya telah masuk dalam peraturan perundang-undangan, yaitu dengan mempertimbangkan hasil penelitian ini dan menetapkan nilai rataan WTP sebesar $\mathrm{Rp} 1.538,65$ per $\mathrm{m}^{3}$ sebagai basis perhitungan dasar tentang nilai pembayaran jasa lingkungan (PJL) dan/atau imbal jasa lingkungan di DAS Cisadane hulu oleh Pemerintah (Daerah) terhadap para pengelola air (users pay principle) untuk masyarakat di hulu karena terdapat potensi dana kompensasi sebagai biaya konservasi untuk penyedia jasa di wilayah hulu dari berbagai kelompok pengelola usaha air minum sebagai pengguna jasa lingkungan (users pay principle), yaitu Rp 106.94 miliar per tahun.

\section{DAFTAR PUSTAKA}

1. Bergh JCJMVD. 2002. Handbook of Environmental and Resource Economics. Edward Elgar. United Kingdom.

2. Mawardi MI. 2009. Krisis Sumber Daya Air di Pulau Jawa dan Upaya Penanganannya: Proyeksi Tahun 2025. "Orasi Pengukuhan Profesor Riset Bidang Hidrologi dan Konservasi Tanah". 2 Desember 2009.BPPT-LIPI. Penerbit IPB Press. Bogor.

3. Gunawan T, Sukwarjono, Zuharnen, N Khakhin, Sutanto. 2001. Teknologi Otomasi Kartografi dalam Pemodelan Atlas Sumberdaya Air di Pulau JawaIndonesia. Laporan Penelitian Proyek Pengkajian dan IImu Pengetahuan dan Terapan, Direktorat Pembinaan Penelitian dan Pengabdian pada Masyarakat, Ditjen Pendidikan Tinggi. Departemen Pendidikan Nasional.

4. Ahlheim M, W Buchholz. (siap terbit). WTP or WTA-Is that the Question? Reflections on the Difference between "Willingness to Pay" and "Willingness to Accept".

5. Fauzi A. 2006. Ekonomi Sumber Daya Alam dan Lingkungan. Teori dan Aplikasi. PT Gramedia Pustaka Utama. Jakarta.

6. Narimawati U. 2008, Teknik-teknik Analisis Multivariat untuk Riset Ekonomi. Graha IImu. Yogyakarta.

7. Uyanto SS. 2009. Pedoman Analisis Data dengan SPSS. Edisi 3. Graha IImu. Yogyakarta.

8. Putri EIK. 2002. Partizipativen Ansatzen am Beispiel des Gunung Gede Pangrango Nationalparks in Indonesien. Cuvilier verlag Gottingen. German. 